\title{
Identification of Fuel Cycle Simulator Functionalities for Analysis of Transition to a New Fuel
}

Cycle

Nicholas R. Brown, ${ }^{\mathrm{a},{ }^{*}}$ Brett W. Carlsen, ${ }^{\mathrm{b}}$ Brent W. Dixon, ${ }^{\mathrm{b}}$ Bo Feng, ${ }^{\mathrm{c}}$ Harris R. Greenberg, ${ }^{\mathrm{d}}$ Ross D. Hays, ${ }^{\mathrm{b}}$ Stefano Passerini, ${ }^{\mathrm{c}}$ Michael Todosow, ${ }^{\mathrm{e}}$ Andrew Worrall ${ }^{\mathrm{a}}$

a Oak Ridge National Laboratory: Building 5700, Room H212, Mail Stop 6165; Oak Ridge

National Laboratory; Oak Ridge, Tennessee 37830; USA; brownnr@ornl.gov

${ }^{\mathrm{b}}$ Idaho National Laboratory, 2525 Fremont Avenue, Idaho Falls, ID 83402, USA

${ }^{c}$ Argonne National Laboratory, 9700 Cass Ave, Lemont, IL 60439, USA

${ }^{d}$ Lawrence Livermore National Laboratory, 7000 East Ave, Livermore, CA 94550, USA

${ }^{\mathrm{e}}$ Brookhaven National Laboratory, 2 Center St, Upton, NY 11973, USA

*Corresponding author; prior affiliation, Brookhaven National Laboratory

\section{ABSTRACT}

Dynamic fuel cycle simulation tools are intended to model holistic transient nuclear fuel cycle scenarios. As with all simulation tools, fuel cycle simulators require verification through unit tests, benchmark cases, and integral tests. Model validation is a vital aspect, as well. Although comparative studies have been performed, there is no comprehensive unit test and benchmark library for fuel cycle simulator tools. The objective of this paper is to identify some of the "must test" functionalities of a fuel cycle simulator tool within the context of specific problems of interest to the Fuel Cycle Options Campaign within the U.S. Department of Energy's Office of Nuclear Energy (DOE-NE). This paper identifies the features needed to cover the range of promising fuel cycle options identified in the DOE-NE Fuel Cycle Evaluation and Screening and categorizes these features to facilitate prioritization. Features are categorized as essential functions, integrating features, and exemplary capabilities. A library of unit tests applicable to each of the essential functions should be developed as future work. An international dialog on the functionalities and standard test methods for fuel cycle simulator tools is encouraged.

Key Words: Fuel cycle simulator, transition analysis, unit tests.

This manuscript has been authored by UT-Battelle, LLC under Contract No. DE-AC05-00OR22725 with the U.S. Department of Energy. The United States Government retains and the publisher, by accepting the article for publication, acknowledges that the United States Government retains a non-exclusive, paid-up, irrevocable, world-wide license to publish or reproduce the published form of this manuscript, or allow others to do so, for United States Government purposes. The Department of Energy will provide public access to these results of federally sponsored research in accordance with the DOE Public Access Plan (http://energy.gov/downloads/doe-public-access-plan ). 


\section{INTRODUCTION}

In 2011, the U.S. Department of Energy Office of Nuclear Energy (DOE-NE) chartered the nuclear fuel cycle Evaluation and Screening (E\&S) study [1] to identify nuclear fuel cycle options that offer significant potential benefits versus the present once-through fuel cycle with light water reactors (LWRs). These benefits are related to performance in key areas like natural resource utilization and nuclear waste generation. Thousands of possible nuclear fuel cycles were identified and grouped based on fundamental physics characteristics, including feed material, the neutron energy spectrum of the reactor stage, and recycled materials. The E\&S identified a promising fuel cycle at an equilibrium condition (steady state), but was not focused on issues associated with the transition from the present fuel cycle to a potential future fuel cycle.

Fuel cycle simulator tools can inform time-dependent nuclear fuel cycle scenarios and performance [2]. This includes a transition from the present well-understood once-through fuel cycle to a future fuel cycle that presents significant potential economic, resource utilization, and environmental benefits relative to the present fuel cycle in the United States. The goal is to develop a once-through fuel cycle with enrichment using thermal spectrum reactors. Significant effort has recently been devoted to the development of fuel cycle simulator tools and simulation frameworks. Examples of fuel cycle simulation tools used within the Fuel Cycle Options Campaign include CYCLUS [3, 4], DANESS [5], DYMOND [6], ORION [7], and VISION [8]. The development of these tools required testing and verification. In addition, the scenario models developed using these tools must be validated. 
Previous benchmark and comparison studies between these and other fuel cycle codes were often conducted for complete fuel cycle scenarios involving entire fleets with different reactor types, specific energy demand profiles, various fuel cycle facilities, etc., and the level of agreement depended greatly on the specific scenarios modeled. Therefore, successful code verification for one specific scenario (e.g., transition from thermal spectrum reactors to fast spectrum reactors) does not imply that the same codes will agree for a different scenario with even small differences. Therefore, this paper proposes that these codes should be tested for their specific fundamental functionalities via a common library of "unit tests" rather than for specific scenarios in order to isolate the true sources of differences.

One general challenge that fuel cycle simulators face is the validation process; there may be ambiguities in the correct answer for problems and a lack of hard data for validation of models and verification of tools. Also, the problems these simulators tackle are complex, with many loosely and strongly coupled interactions between systems and material flows. These challenges were evident in two recent benchmark studies focused on complex integral scenarios $[9,10]$. Therefore, these unit tests must be clear in their specifications to avoid multiple interpretations from different participants.

There is a need to develop unit tests for fuel cycle simulator tool verification. In addition to the unit tests, there is interest in more realistic (but still simplified) transition scenario cases that test the comprehensive capabilities of the simulator. Both of these types of test cases are vital for verification of a fuel cycle simulator. Therefore, it is proposed to develop a library of unit test cases that would be useful for tool developers worldwide to use for testing functionalities and verification of possible 
transition scenarios. This focus dovetails with the main purpose of most fuel cycle simulators: to study scenarios for transition from the existing fleet to a new fuel cycle system.

A key question in defining test cases for studying transition to a promising future fuel cycle is: what are the problems we are trying to solve and what functionalities are necessary to solve them? This question is part of the overall goal to identify fuel cycles with significant benefits to the current once-through fuel cycle in the United States. This goal requires study of methods to transition from the present situation to advanced cycles. This transition study identifies constraints on the rate at which transition to an advanced fuel cycle can be achieved.

Several fuel cycles are considered qualitatively herein, and particular features of interest/relevance for each cycle are identified. A three-tier hierarchy of features was considered:

- Basic features or essential functionalities are foundational elements of the simulation; they represent the basic building blocks.

- Integral features are necessary to bind the essential functionalities together and produce useful transition results.

- Finally, exemplary features enable a particular tool to study particular sensitivities, technology choices, etc., but they may not be essential or present in every tool.

Fuel cycles were selected for the scope of this paper with the goal of identifying and documenting essential functionalities for modeling those fuel cycles in a fuel cycle simulator (including those at 
the front end, back end, and reactor/transmutation stages). The example fuel cycles in this document are from the comprehensive E\&S study [1].

The objective of the E\&S study was to evaluate nuclear fuel cycle options and identify those that offer significant potential benefits compared to the present once-through fuel cycle with light water reactors. These performance benefits are in key areas such as natural resource utilization and generation of nuclear waste. Thousands of options were considered in the study and were condensed into forty evaluation groups (EGs) with fundamental physics characteristics, such as material feed and neutron energy spectrum.

Three fuel cycles are considered in this paper: (1) once-through low-enriched enriched uranium (LEU) in thermal spectrum reactors (EG01), (2) continuous recycle of uranium and plutonium in fast spectrum reactors (EG23), and (3) continuous recycle of thorium and uranium (mostly $\left.{ }^{233} \mathrm{U}\right)$ in fast reactors (EG28). Short descriptions and justifications for these fuel cycles are shown in Table 1. Each fuel cycle is a single-stage fuel cycle, i.e., one reactor type only. However, because the transition from one fuel cycle to another is inherently a multi-stage problem, the scope of this paper covers the behavior of multi-stage fuel cycles. Multiple facilities and fuel types are needed to model each of these transition problems. Transitions to multi-stage fuel cycles, such as continuous recycle of uranium and plutonium in fast reactors with uranium and plutonium also used in thermal reactors (EG29), share similar functionalities as EG23 but have added constraints and questions. One key question is: what strategy should be used in deploying the reactors in the different stages of the two-stage fuel cycle? This is an important question, but it was determined that this and similar 
questions for two-stage fuel cycles are outside the scope of the present paper.

This paper identifies the features needed to model a transition scenario from the present fuel cycle to continuous recycle of $\mathrm{U}-\mathrm{Pu}$ or Th-U3 in fast spectrum reactors. In this paper $\mathrm{U} 3$ is a uranium vector that contains ${ }^{233} \mathrm{U}$ as the primary fissile isotope, but also includes ${ }^{234} \mathrm{U},{ }^{235} \mathrm{U}$, and other uranium isotopes. A transition scenario begins with a fleet of legacy LWR reactors which use low-enriched uranium (LEU) fuel. The new fuel cycle is then deployed using some source of fissile material. The transition scenarios relevant to this study are those in which the present once-through fuel cycle transitions over a period of time to an advanced future fuel cycle with significant potential benefits. This study represents an initial identification of basic features associated with transition to two specific fuel cycles. Other features may be associated with transition to other fuel cycles. This paper also includes an example of a possible unit test, a fixed rate of growth in nuclear energy demand. 
Table 1. Example fuel cycles for identification of essential functionalities

\begin{tabular}{|c|c|c|}
\hline Fuel cycle option & Description & Justification \\
\hline EG01 & $\begin{array}{l}\text { Once-through thermal } \\
\text { reactor with } \\
\text { low-enriched uranium } \\
\text { fuel }\end{array}$ & $\begin{array}{l}\text { - Status quo low-enriched uranium thermal reactors, } \\
\text { - This case represents the initial condition in a potential } \\
\text { transition to a sustainable nuclear fuel cycle. }\end{array}$ \\
\hline EG23 & $\begin{array}{l}\text { Continuous recycle of } \\
\text { uranium-plutonium in } \\
\text { fast reactors }\end{array}$ & $\begin{array}{l}\text { - Recycling of } \mathrm{U} / \mathrm{Pu} \text {, in fast reactors, } \\
\text { - This fuel cycle was identified as one of the most } \\
\text { promising fuel cycles in the E\&S [1]. }\end{array}$ \\
\hline EG28 & $\begin{array}{l}\text { Continuous recycle of } \\
\text { thorium-uranium } \\
\text { (mostly }{ }^{233} \mathrm{U} \text { ) in fast } \\
\text { reactors }\end{array}$ & $\begin{array}{l}\text { - Th/U3 fuel, in fast reactors, } \\
\text { - This fuel cycle was identified as a promising fuel } \\
\text { cycle in the E\&S [1]; uses thorium-based fuels. }\end{array}$ \\
\hline
\end{tabular}

\section{GENERAL OVERVIEW OF FUEL CYCLE SIMULATOR FEATURES}

Common functionalities were identified that spanned the transition to each of these sustainable fuel cycles (or a subset of the fuel cycles) in Table 1. Specific examples are highlighted below.

\subsection{Material Compositions}

The backbone of a fuel cycle simulation involves the flow of fuel materials through the system. Modeling of these fuel materials must include the primary fissile and fertile actinide isotopes $\left({ }^{232} \mathrm{Th}\right.$, ${ }^{233} \mathrm{U},{ }^{235} \mathrm{U},{ }^{238} \mathrm{U},{ }^{239} \mathrm{Pu},{ }^{240} \mathrm{Pu},{ }^{241} \mathrm{Pu}$ ) to allow for modeling of fuel enrichment and depletion. The remaining fuel's initial heavy metal mass must also be modeled as a minimum as lumped masses of the remaining actinides and fission products so that a material balance can be maintained. Isotopic decay of materials in storage becomes a requirement as additional isotopes are modeled, or if the quantity or importance of ${ }^{241} \mathrm{Pu}$ is significant. Modeling of intermediate isotopes may also be required if their half-lives approach or exceed the modeling timestep (e.g. ${ }^{233} \mathrm{~Pa}$ in the thorium cycle). Tracking 
of fission products beyond a simple lumped sum is exemplary but often included so that waste properties or material storage/transportation/handling issues (radiotoxicity, decay heat, etc.) may be estimated. Modeling of compounding/alloying/binding materials in fuels and waste forms (e.g., oxygen in $\mathrm{UO}_{2}$ ) and associated hardware/packaging are also exemplary and rarely included. The example material composition features identified in this paper are shown in Table 2.

Table 2. Example material composition features

\begin{tabular}{ll}
\hline Feature & Hierarchy \\
\hline $\begin{array}{l}\text { Modeling of fuel materials including primary fissile and fertile actinide } \\
\text { isotopes }\left({ }^{232} \mathrm{Th},{ }^{233} \mathrm{U},{ }^{235} \mathrm{U},{ }^{238} \mathrm{U},{ }^{239} \mathrm{Pu},{ }^{240} \mathrm{Pu},{ }^{241} \mathrm{Pu}\right)\end{array}$ & Basic \\
\hline $\begin{array}{l}\text { The remaining fuel's initial heavy metal mass modeled as lumped masses } \\
\text { of the remaining actinides and fission products to conserve mass }\end{array}$ & Basic \\
\hline $\begin{array}{l}\left.\text { Isotopic decay of materials in storage (including }{ }^{241} \mathrm{Pu}\right) \\
\text { Modeling of intermediate isotopes (e.g. }{ }^{233} \mathrm{~Pa} \text { in the thorium cycle) }\end{array}$ & Exemplary \\
\hline $\begin{array}{l}\text { Tracking of fission products beyond a simple lumped sum } \\
\text { Modeling of compounding/alloying/binding materials in fuels and waste } \\
\left.\text { forms (e.g., oxygen in } \mathrm{UO}_{2}\right)\end{array}$ & \begin{tabular}{l} 
Exemplary \\
\hline
\end{tabular} \\
\hline
\end{tabular}

\subsection{Deployment of Fuel Cycle Facilities}

Facility (e.g., reactor, front end, fabrication, separations, back-end) deployment is a necessary functionality to simulate transition to an advanced fuel cycle. These facilities may be deployed and retired according to an appropriate prescribed schedule and associated lifetime. Construction time delays are also relevant basic functionalities. Strategic deployment of appropriate facilities to meet nuclear demand is an integral functionality. Significant overlap is expected in this area because all fuel cycles require deployment and retirement of facilities. Proposed tests include modeling a single 
reactor or fuel cycle facility through its lifetime to ensure proper accounting of construction lead time, operational functionality, capacity utilization, and retirement. The example material composition features identified in this paper are shown in Table 3.

Table 3. Example fuel cycle facility deployment features

\begin{tabular}{ll}
\hline Feature & Hierarchy \\
\hline $\begin{array}{l}\text { Facility (e.g., reactor, front end, fabrication, separations, back-end) dep- } \\
\text { loyment and retirement }\end{array}$ & Basic \\
Construction time delays & Basic \\
Strategic deployment of appropriate facilities to meet nuclear demand & Integral \\
\hline
\end{tabular}

\subsection{Front-End Facility Models}

Required models include a source (mining and milling or recycling) that may include both uranium and thorium feedstock. The specific details of mines and mills are seldom modeled and are not necessary except as an indication of the annual and total quantities available. However, conversion may be modeled (mainly for economics), and enrichment is typically modeled (required for mass flows). The timing and capacity of recycle facilities are also typically required. Collectively, these facilities would be necessary for each fuel feed for a given fuel cycle. The fuel cycles fall broadly into two categories: (1) the first pass, which is unirradiated uranium fabrication, and (2) recycled fuel fabrication, which is a mix of unirradiated and previously irradiated recycled $\mathrm{U} / \mathrm{Pu}$ or U/TRU or Th/U3 (with or without TRU) fabrication. This will include some delta time between mining/milling/conversion and fabrication or separations and fabrication (fabrication time). Losses in fabrication $(0.2 \%$ in the E\&S) must be accounted for, because losses to waste are an 
important feature to track. Examples of proposed unit tests include (1) a test of fuel enrichment and burnup (correlated/recipe based), including front-end mining, enrichment, and fabrication facilities (uranium mined, depleted uranium generated, LEU fuel charged and discharged, spent fuel disposed), and (2) a test of the constrained availability of front-end facilities/raw material and verification that the availability of LWR fuel is affected. The example front-end fuel cycle features identified in this paper are shown in Table 4.

Table 4. Example front-end fuel cycle facility features

\begin{tabular}{ll}
\hline Feature & Hierarchy \\
\hline $\begin{array}{l}\text { Source facility (mining and milling or recycling) that may include both ura- } \\
\text { nium and thorium feedstock }\end{array}$ & Basic \\
Details of mines and mills including the annual and total quantities available & Exemplary \\
Conversion and enrichment facilities & Basic \\
Timing and capacity of recycle facilities & Basic \\
Fuel fabrication (fresh and recycle fuel) & Basic \\
Time delays and losses in separations and fabrication & Basic \\
\hline
\end{tabular}

\subsection{Separations and Material Recycling Facilities}

These models will be necessary for tracking spent fuel in a recycle fuel cycle. Depending on the strategy for transition, additional separations facilities may be required for LWR spent fuel, U/Pu, U/TRU, and Th/U3 fuel. Behavior for separations facilities is a necessary functionality that will include a time interval between discharge and separations (cooling time) and the losses in separations (assumed to be $1.0 \%$ in the E\&S).

Apart from the uranium enrichment process, there are very few ways to alter the isotopic vectors of any material stream. This limitation has several key impacts for any fuel cycle simulation model. The first impact is to material selection from the available spent fuel supply in order to match a given 
recycled fuel specification. In other words, we are constrained to a given set of spent fuel compositions to match a specified fuel recipe intended for recycled fuel (i.e., the "winery problem"). Beyond the selection of recycled feed materials, variations in isotopic vectors going into a reactor will lead to corresponding variations in the spent fuel coming out. At the level of the fuel cycle simulation model, many of these complications are avoided through the use of simplifying assumptions, such as assuming the fungibility of isotopic vectors to meet a given fixed fuel recipe. Wherever possible, the impact of these simplifying assumptions should be assessed either through simple test cases or through comparisons with separate analyses. For example, the VISION fuel cycle simulator can enforce conservation of total $\mathrm{Pu}$ (or TRU, etc.) mass when creating fuel from recycled material; in doing so, it tracks the isotopic mass discrepancy created by this assumption. This discrepancy should be evaluated to ensure that it does not represent a significant error with respect to any of the fuel cycle metrics under consideration. The example separations and material recycling features identified in this paper are shown in Table 5.

Table 5. Example separations and material recycling features

\begin{tabular}{ll}
\hline Feature & Hierarchy \\
\hline Separations facilities may be required for LWR spent fuel, U/Pu, U/TRU, and & Basic \\
Th/U3 fuel & Basic \\
\hline Time interval between discharge and separations (cooling time) & Basic \\
\hline Losses in separations & Basic \\
\hline Material selection from the available spent fuel supply ("winery problem") & \\
\hline
\end{tabular}

\subsection{Reactor Facilities}

Reactor facilities feature fueling requirements. Reactor facilities burn fuel, a process which consists of charge and discharge of driver and blanket fuel with associated residence times. The fuel is 
defined according to pre-generated isotopic from reactor physics calculations ("recipes"), or it is defined by calculations performed in real time based on physics models. Pre-generated isotopic compositions are considered to be an essential feature for the fuel cycles considered in this paper. However, the pre-generated recipes must account for high importance isotopes, such as ${ }^{241} \mathrm{Pu}$, with a relatively short half-life. Real time calculations based on reactor physics models are considered to be exemplary for the example fuel cycles in this paper, but for some other scenarios (such as those with variable cooling time) this feature would be essential. Each reactor will have a prescribed lifetime, construction time, and decommissioning time. The initial charge for the first core and the discharge for the final core must reflect accurate heavy metal mass requirements. Proposed features to be tested include (1) reactor lifetime, construction, deployment, retirement, and associated mass flows, (2) a check that steady state separation stream values do lead to a steady state condition without material accumulation. The example reactor facility features identified in this paper are shown in Table 6 .

Table 6. Example reactor facility features

\begin{tabular}{ll}
\hline Feature & Hierarchy \\
\hline $\begin{array}{l}\text { Reactor facilities fueling requirements, including number of batches, cycle } \\
\text { length, and fuel charge per batch }\end{array}$ & Basic \\
$\begin{array}{l}\text { Multiple fuel types in reactor facility (driver, blanket, etc.) } \\
\text { Pre-generated charge and discharge isotopic compositions }\end{array}$ & Basic \\
Real time calculations based on reactor physics models & Basic \\
\hline Reactor facility lifetime, construction time, and decommissioning time & Exemplary \\
\hline Initial charge for the first core and the discharge for the final core & Basic \\
\hline
\end{tabular}

\subsection{Back-End Features}

Back-end features include cooling of spent fuel that is to be disposed of or recycled. Some specifics on the back end (e.g., the disposal facility) will include conservation of disposed material 
mass and consistency with charge masses and the generated power. Back-end features are necessary for tracking metrics for nuclear waste management. The example back-end fuel cycle facility features identified in this paper are shown in Table 7.

Table 7. Example back-end fuel cycle facility features

\begin{tabular}{ll}
\hline Feature & Hierarchy \\
\hline Cooling of spent fuel that is to be disposed of or recycled & Basic \\
Conservation of disposed material mass and consistency with charge masses & Basic \\
and the generated power & \\
\hline
\end{tabular}

\subsection{Starting the New Fuel Cycle}

Startup is a difficult problem for some fuel cycles due to fissile material requirements because an initial source of fissile material is needed to start the reactors in the fuel cycle. Details on the features of a specific fuel cycle simulator tool are necessary to address multiple fuel cycle starting strategies. Startup of some fuel cycles may be more straightforward than others, but transition to all fuel cycles without enrichment at equilibrium will involve an external source of fissile material. One option is to assume fuel cycle startup using fissile material recovered from spent LWR fuel, but additional strategies exist, including using LEU to start a new fuel cycle. The capability to use more than one material for starting a new fuel cycle is an integral feature. However, many transition scenarios considered to date focus on plutonium start-up of fast reactors, and the codes used to perform that work may not be capable of modeling multiple fuel types for a reactor (primary and back-up fuel). The example fuel cycle startup features identified in this paper are shown in Table 8.

Table 8. Example fuel cycle startup features 


\subsection{Materials Queuing and Prioritization under Capacity Limitations}

A specific transient scenario may feature phases in which materials are allowed to accumulate prior to being moved to their next point of utilization. For example, if $\mathrm{Pu} / \mathrm{U}$ from LWR spent fuel is used to bootstrap the fuel cycle, this material will build up prior to the start of separations, and separated material may build up prior to being fabricated into finished fuel. Wherever material is allowed to accumulate or when there are multiple sources available, decisions must be made regarding the priority order in which the material will be used. The simplifying assumptions used in many fuel cycle simulators may render these issues inactive or untestable for most common scenarios. However, if radioactive decay or time-varying fuel compositions are to be modeled (exemplary features), then care must be taken to ensure that they are handled in a consistent manner between each model. (Note that this may be outside the present scope of unit or integral testing.) The example material prioritization features identified in this paper are shown in Table 9.

Table 9. Example material prioritization features

\begin{tabular}{ll}
\hline Feature & Hierarchy \\
\hline Material accumulation & Basic \\
Material prioritization & Integral and/or Exemplary \\
Radioactive decay or time-varying fuel compositions & Exemplary \\
\hline
\end{tabular}

\subsection{Energy Demand Algorithms}

Information on the features related to energy demand are necessary to enable deployment (or 
retirement) of reactors to meet a change in nuclear energy demand. These features allow for technology penetration allocation and checking for material availability and backup reactor technology. In addition, the algorithm must enable ordering and deployment of multiple reactor technologies at the same time. This is a key feature for integral tests and modeling of actual transition scenarios as opposed to unit tests. Proposed tests include (1) checking that the reactor ordering algorithm is able to cover the assigned energy demand when no material constraints are identified and (2) checking that backup technology is deployed when material constraints are encountered. The example energy demand algorithm features identified in this paper are shown in Table 10.

Table 10. Example energy demand algorithm features

\begin{tabular}{ll}
\hline Feature & Hierarchy \\
\hline Technology allocation accounting for availability & Integral \\
Ordering and deployment of multiple reactor technologies & Integral \\
\hline
\end{tabular}

\section{EXAMPLE FEATURES OF SPECIFIC NUCLEAR FUEL CYCLES}

This section of the paper explores identified features specific to a particular fuel cycle. In some cases, possible unit tests or integral tests are proposed to address these features.

\subsection{Once-Through Thermal Reactor with LEU Fuel (EG01)}

The EG01 scenario, which serves as the reference fuel cycle in the E\&S, is representative of the present U.S. once-through fuel cycle. However, it is notable that the present U.S. fuel cycle does not have a permanent repository. LEU oxide fuel is irradiated in existing commercial pressurized water reactors (PWRs) to approximately the current LWR average discharge burnup $(\sim 50 \mathrm{GWd} / \mathrm{t})$. 
Discharged fuel (DF) is cooled in onsite spent fuel storage and sent to a geologic disposal (see material flow diagram in Fig. 1). The major focus of this paper is on identification of features to simulate the potential transition from EG01 to another fuel cycle.

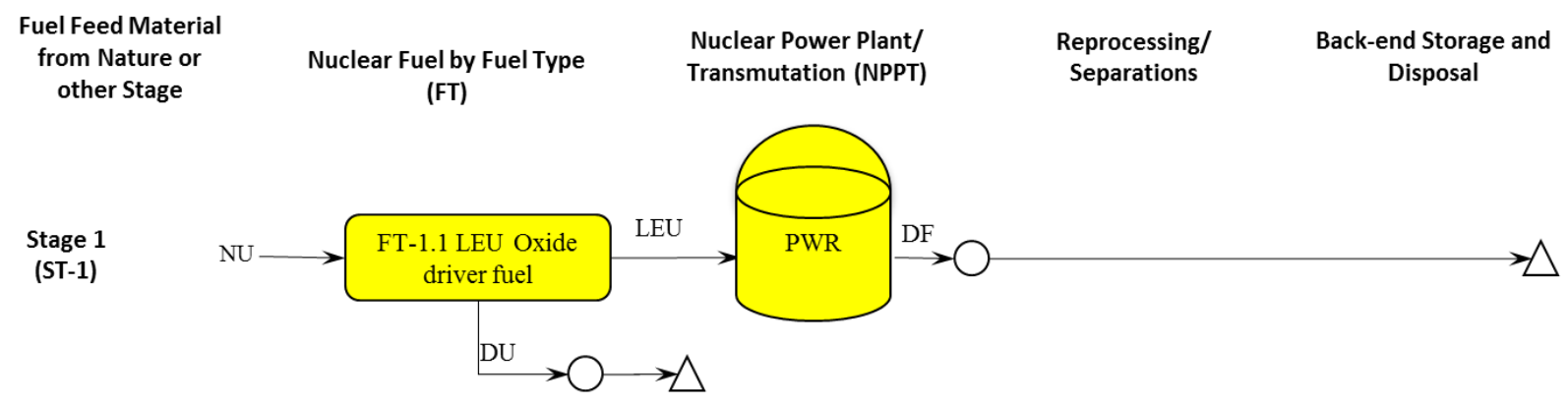

Note: Only primary material flows are shown. Material flows from imperfect separations (losses), low-level waste, and other secondary streams that will be produced in performing various fuel cycle functions are not shown.

Legend:

$\mathrm{NU}=$ Natural Uranium

$\mathrm{DU}=$ Depleted Uranium

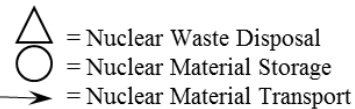

Fig. 1. EG01 [1] fuel cycle material flow.

Potential functionalities were identified for the modeling of a once-through fuel cycle with LEU in LWRs. One essential feature is the tracking of radioactive decay and related properties (activity, radiotoxicity, and decay heat). These properties will directly impact fuel cycle performance metrics related to nuclear waste management.

Another key issue relates to the reactor mix in the present U.S. nuclear fuel cycle. About two-thirds of the current LWR fleet is made up of PWRs, and the remaining third is boiling water reactors (BWRs). Distinguishing the reactor types is an essential functionality for simulation tools. In 
addition, instead of modeling a single reactor specification and set of assumptions, the simulator could include the functionality to model a realistic set of different combinations of reactor burnups, enrichments, refueling times, and licensed operational lifetimes.

\subsection{Continuous Recycle of U/Pu in Fast Reactors (EG23)}

There are several existing approaches exist for transition from the LWR system to a system with breakeven $\mathrm{U} / \mathrm{Pu}$ fueled sodium fast reactors (SFRs). In this context breakeven means that the fissile inventory ratio is unity, after accounting for losses and isotopic change due to transmutation and isotopic decay in cooling. Options include using LWR spent fuel (legacy or accumulated after a set time) or LEU fuel. At the specified time, the LWR spent fuel is recycled, with uranium and plutonium being used as fuel for a fleet of breakeven sodium fast reactors that replace the retiring LWR fleet. New LWRs may be built as needed to replace legacy reactors retiring prior to the availability of the new SFR reactors or if the recycled material should be insufficient to meet the overall power demands. The EG23 fuel cycle is shown in Fig. 2. 


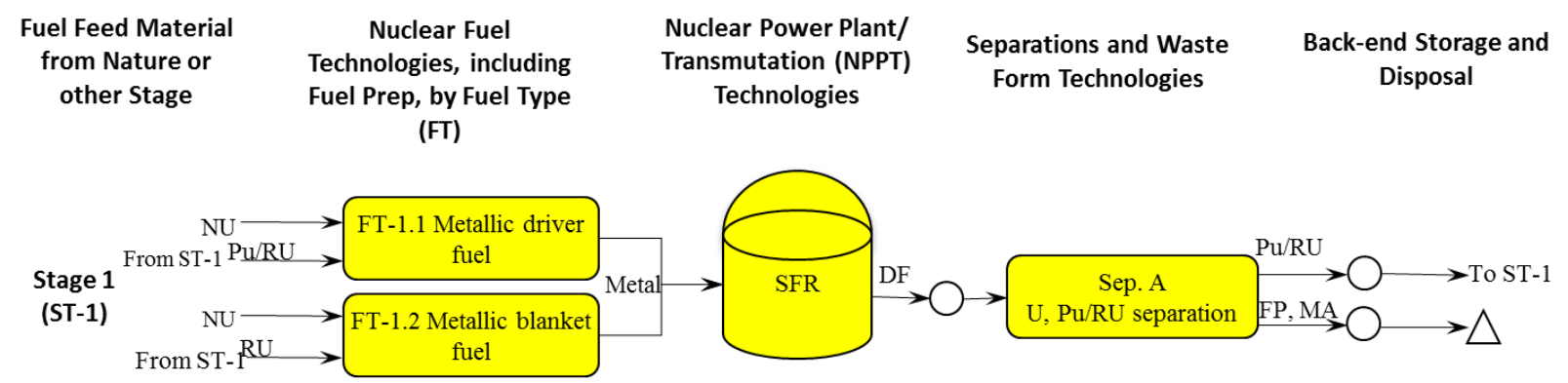

Note: Low-Level Waste (LLW) will be produced in performing various fuel cycle functions. Legend:

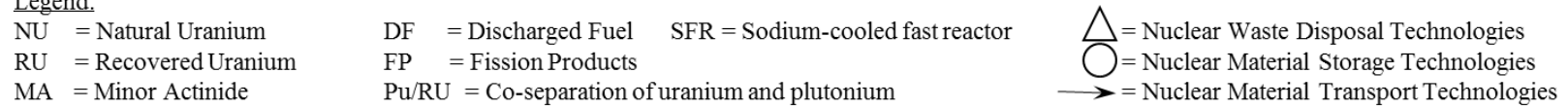

Fig. 2. EG23 [1] fuel cycle material flow.

To ensure that each fuel cycle simulator is functioning as intended and to provide a basis for comparisons within the code, a few key features of each simulator should be closely evaluated, some of which are described below. These features will apply to many scenarios besides the one described here.

The EG23 fuel cycle uses recycled material at equilibrium. To transition from the equilibrium EG01 fuel cycle to the EG23 fuel cycle requires an approach for starting the fuel cycle. There are at least two strategies for starting the fuel cycle: (1) using LWR spent fuel or (2) using LEU fuel directly in the SFR. Simple tests and the ability to switch charge vector are therefore relevant for this fuel cycle. The driver and blanket represent separate charge fuel streams and therefore will require separate front-end facilities. 


\subsection{Continuous Recycle of Th/U3 in Fast Reactors (EG28)}

EG28 is a challenging transition problem because thorium fertile fuel is used and the primary fissile nuclide $\left({ }^{233} \mathrm{U}\right)$ does not exist in nature, nor is it a product of the present once-through LWR fuel cycle. The mass flow diagram for EG28 is shown in Fig. 3.

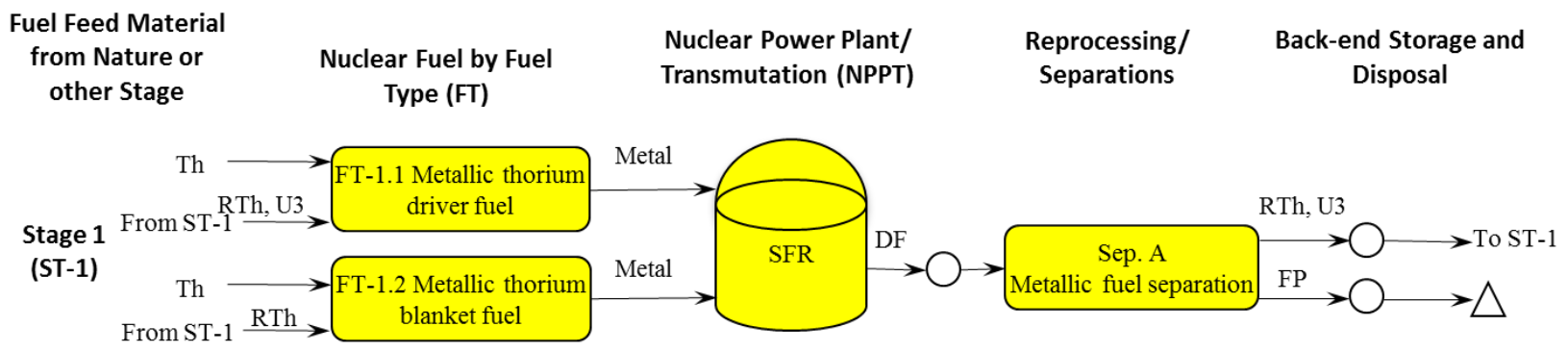

Note: Only primary material flows are shown. Material flows from imperfect separations (losses), low-level waste, and other secondary streams that will be produced in performing various fuel cycle functions are not shown. Legend:

Th = Natural Thorium $\quad$ DF $=$ Discharged Fuel $\quad$ SFR = Sodium Fast Reactor $\triangle=$ Nuclear Waste Disposal RTh = Recovered Thorium $\quad$ FP = Fission Products $\quad$ U3 = Trans-thorium(mostly U-233)

Fig. 3. EG28 [1] fuel cycle material flow.

Transition from the present once-through fuel cycle to EG28 presents unique considerations and constraints. EG28 will require an external source of fissile material to be deployed. This would likely be LEU driver fuel, U/Pu (or TRU) fuel from LWR spent fuel, or Th/Pu (or TRU) driver fuel with the $\mathrm{Pu}$ (or TRU) recovered from LWR spent fuel. The SFRs would initially be fueled by the external source of fissile material with pure Th blankets, and eventually enough U3 would build up to begin fueling reactors with their intended feed material. 
This transition requires the functionality to shift from one fuel input to another for a single reactor type. In other words, the initial feed to an EG28 SFR would consist of an external source of fissile material, such as LEU driver fuel, as well as Th blanket fuel. The Th blanket fuel would be reprocessed, and the $\mathrm{U} 3$ vector ( $\mathrm{U}$ isotopics resulting from the Th cycle) would be co-extracted with Th and stockpiled for eventual deployment as driver fuel for SFRs. When enough fuel is built up, the charge recipe for the driver fuel would shift to the intended driver fuel for the fuel cycle: Th/U3.

Depending on the transition strategy (for example, if U/Pu driver fuel recycled from LWR spent fuel is used), multiple separations or fuel fabrication facilities may be required for a single reactor.

\section{EXAMPLE UNIT TEST FOR GROWTH IN ENERGY DEMAND}

An example unit test case is described for a growth scenario. In this scenario, reactors are deployed to meet a fixed growth rate in nuclear energy demand (in this case $1 \%$ per year beginning with a $100 \mathrm{GWe}$ capacity). The functionalities tested by this example case are:

- reactor deployment according to a growing energy demand,

- steady state operation with an infinite source of fuel,

- material flow tracking in the reactor,

- accumulation of spent fuel in cooling storage and dry storage, and

- time delays associated with cooling storage.

Additional parameters of this example unit test are shown in Table 11. This example scenario was $20 / 26$ 
solved in four fuel cycle simulator tools: CYCLUS, DYMOND, ORION, and VISION. The

analytical solution was used to compare the different simulator tools. All of the tools exhibited results

consistent with their respective architectures for deployment of facilities to meet demand, the

definition of the test, and the interpretation of the test by a particular analyst. This example is intended

to demonstrate one possible approach to testing a few basic features.

Table 11. Parameters for example unit test for $1 \%$ growth in nuclear energy demand

\begin{tabular}{|c|c|}
\hline Duration & 200 years [Begin year 0; end year 199] \\
\hline Mining & There is no modeling of mining features in this unit test. \\
\hline Fabrication & There is no modeling of fabrication features in this unit test. \\
\hline Fuel & $\begin{array}{l}\text { No specific fuel composition features are used in this test case. An infinite supply of } \\
\text { generic reactor fuel is assumed. }\end{array}$ \\
\hline Deployment & $\begin{array}{l}\text { A } 100 \mathrm{GWe} \text { generic reactor capacity exists at the beginning of the simulation. The } \\
\text { capacity factor is } 0.9 \text {, so the electricity generated is } 90 \text { GWe per year. After } \\
\text { deployment, the reactor operates at steady state throughout the duration of the } \\
\text { simulation. } \\
\text { Each year the energy demand grows by } 1 \% \text {, so } 100 \mathrm{GWe} \text { capacity in year } 0 \text { becomes } \\
101 \text { GWe in year } 1 \text { (compounded annually), and so on. Reactors ( } 1 \text { GWe capacity) } \\
\text { are deployed as needed to meet the energy demand. }\end{array}$ \\
\hline Retirement & There is no modeling of facility retirement features in this unit test. \\
\hline $\begin{array}{l}\text { Core loading } \\
\text { and discharge }\end{array}$ & $\begin{array}{l}\text { The total initial core loading of a deployed reactor is } 90 \mathrm{t} \text { of heavy metal. The } \\
\text { annual core charge per reactor is } 19.909 \mathrm{t} / \mathrm{yr} \text {, and core discharge is } 19.909 \mathrm{t} / \mathrm{yr} \text {. } \\
\text { Annual loading and discharge occur at the beginning of each year, from year } 0 \\
\text { throughout the duration of the simulation. } \\
\text { The generic reactors operate on } 19.909 \mathrm{t} / \mathrm{yr} \text { of an unlimited supply of heavy metal. }\end{array}$ \\
\hline $\begin{array}{l}\text { Wet and dry } \\
\text { storage }\end{array}$ & $\begin{array}{l}\text { The discharged fuel is cooled in wet storage for a total of } 4 \text { years. The first discharge } \\
\text { enters wet storage at the beginning of year } 1 \text {, and this continues throughout the } \\
\text { duration of the simulation. } \\
\text { After cooling, the fuel is moved to dry storage, where it accumulates throughout the } \\
\text { duration of the simulation. The first batch of fuel is moved from wet storage to dry } \\
\text { storage immediately at the beginning of year } 5 \text {. }\end{array}$ \\
\hline
\end{tabular}



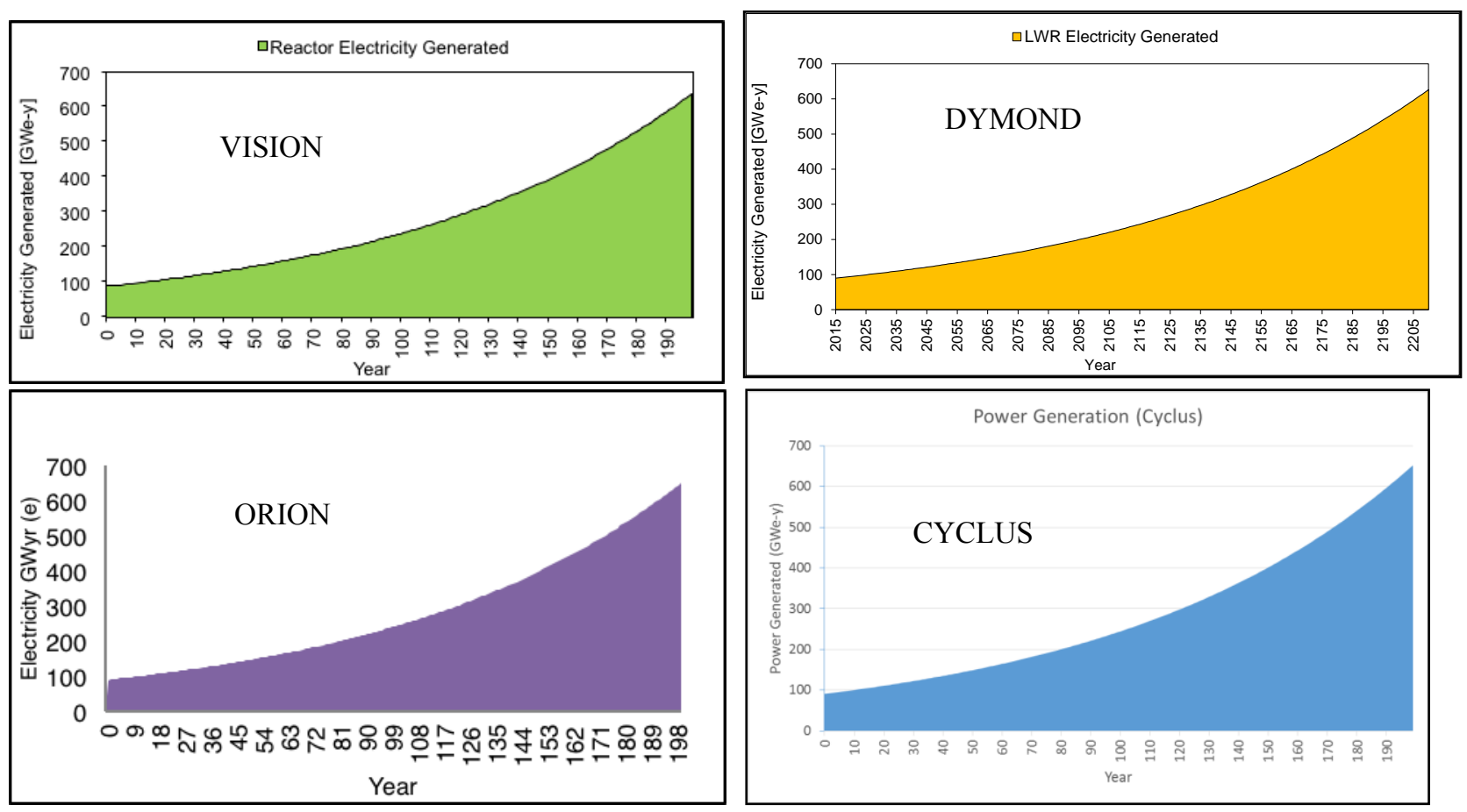

Fig. 4. Example solutions to a unit test for $1 \%$ annual growth in demand for nuclear energy.

This paper is focused on identifying functionalities that may be relevant for unit tests given example transition problems to several example fuel cycles. This paper is not intended to define the unit tests themselves. The unit test shown in Table 11 is just an example. The objective of this paper is not to fully prescribe these tests or features, but rather to present the results of one expert elicitation focused on the identification of general observations about needed features and limited identification of potential specific functionalities to test.

\section{SUMMARY AND FUTURE WORK}

Example functionalities relevant to solving a particular type of transient problem for a fuel cycle simulator are identified. The transient problem in question is a scenario in which a once-through 
nuclear fuel cycle with LEU in thermal reactors transitions to a sustainable advanced fuel cycle. Some example basic features and exemplary features are identified for two potential future fuel cycles.

This work defines the basic features of fuel cycle simulator tools. These functionalities support the development of unit test cases to perform verification of the proposed tools. Functionality outside the basic features' scope is also important, and added capabilities must be tested and verified by the developers of the particular tools.

Basic features must be subjected to verification via unit tests. The value of simplified, standardized, and open cases has been noted in the literature [11]. However, even the cases identified in Reference 9 have significant complexity and competing effects. Test cases with a simplified basis are needed to enable quality assurance while avoiding error cancellation. In addition, the analytical solutions to the test cases must be unambiguous. There is added value in having a set of strictly defined test cases for dynamic fuel cycle simulators.

These basic features are a platform to potentially develop an open library of unit tests. These unit test cases would serve as the building blocks for development of more sophisticated cases. The unit tests are focused on isolating particular features or modules and verifying that behavior is in accordance with the expected result given the architecture of a particular tool. Unit tests serve as the foundation of a holistic benchmarking effort, which would eventually include integral test cases of entire transition scenarios [12]. The effort in the present paper is complementary to previous efforts to develop essential requirements document for fuel cycle simulators and taking a comparative 
inventory of these simulators [13].

\section{ACKNOWLEDGMENTS}

Jennifer Littell of the University of Tennessee-Knoxville is gratefully acknowledged for her CYCLUS solution to the example unit test.

This work was supported by the U.S. Department of Energy Office of Nuclear Energy Fuel Cycle Options Campaign.

This manuscript has been authored by UT-Battelle, LLC, under Contract No. DE-AC0500OR22725 with the U.S. Department of Energy. The United States Government retains and the publisher, by accepting the article for publication, acknowledges that the United States Government retains a non-exclusive, paid-up, irrevocable, world-wide license to publish or reproduce the published form of this manuscript, or allow others to do so, for the United States Government purposes. The Department of Energy will provide public access to these results of federally sponsored research in accordance with the DOE Public Access Plan (http://energy.gov/downloads/doe-public-access-plan).

\section{REFERENCES}

[1] R. Wigeland, T. Taiwo, H. Ludewig, M. Todosow, W. Halsey, J. Gehin, R. Jubin, J. Buelt, S. Stockinger, K. Jenni and B. Oakley, "Nuclear fuel cycle evaluation and screening — final report." Idaho National Laboratory Technical Report INL/EXT-14-31465 (2014). See: http://fuelcycleevaluation.inl.gov/

[2] K. Huff, B. Dixon "Next Generation Fuel Cycle Simulator Functions and Requirements 
Document," Idaho National Laboratory Technical Report FCRD-SYSA-2010-000110 (2010).

[3] K. D. Huff, P. H. Wilson, M. J. Gidden, “Open Architecture and Modular Paradigm of CYCLUS , a Fuel Cycle Simulation Code,” Trans Am Nuc Soc 104, pp 183-184 (2011).

[4] K. D. Huff, M. J. Gidden, R. W. Carlsen, R. R. Flanagan, M. B. McGarry, A. C. Opotowsky, E. A. Schneider, A. M. Scopatz, and P. PH Wilson. "Fundamental Concepts in the Cyclus Fuel Cycle Simulator Framework.” Advances in Engineering Software, 94, 46-59 (2016).

[5] L. Van Den Durpel, A. Yacout, D. Wade, H. Khalil, "DANESS: Dynamic Analysis of Nuclear Energy System Strategies," in Proc. of the Global 2003 Conference, New Orleans, LA, USA, November 16-20, 2003, American Nuclear Society, LaGrange Park, IL, USA (2003).

[6] A. M. Yacout, R. N. Hill, L. Van Den Durpel, P. J. Finck, E. A. Schneider, C. G. Bathke and J. S. Herring, "Dynamic Analysis of the AFCI Scenarios," PHYSOR 2004, April 25-29, 2004, Chicago, IL, USA (2004).

[7] A. Worrall, R. Gregg, "Scenario Analyses of Future UK Fuel Cycle Options," Journal of Nuclear Science and Technology 44, 249-256 (2007).

[8] J. J. Jacobson, A. M. Yacout, G. E. Matthern, S. J. Piet, D. E. Shropshire, R. F. Jeffers, T. Schweitzer, "Verifiable Fuel Cycle Simulation Model (VISION): A Tool for Analyzing Nuclear Fuel Cycle Futures," Nucl Technol 172, pp 157-178 (2010).

[9] OECD/NEA, "Benchmark Study on Nuclear Fuel Cycle Transition Analysis Codes," NEA/NSC/WPFC/DOC(2012)16 (2012).

[10]L. Guérin, et al., “A Benchmark Study of Computer Codes for System Analysis of the Nuclear Fuel Cycle,” Nuclear Fuel Cycle Program, MIT-NFC-TR-105 (April 2009).

[11]M. Gidden, A. Scopatz, P. Wilson, "Developing Standardized, Open Benchmarks and a 
Corresponding Specification Language for the Simulation of Dynamic Fuel Cycle," Trans Am Nuc Soc 108, pp 127-130 (2013).

[12]B. Feng, B. Dixon, E. Sunny, A. Cuadra, J. Jacobson, N. R. Brown, J. Powers, A. Worrall, S. Passerini, R. Gregg, “Standardized Verification of Fuel Cycle Modeling," Annals of Nuclear Energy 94, 300-312 (2016)..

[13]C. A. Juchau, C. A., M. L. Dunzik-Gougar, M. L., J. J. Jacobson, "Modeling the nuclear fuel cycle," Nuclear technology, 171(2), 136-141 (2010). 